\title{
Correction to: Caribbean corals exhibit species-specific differences in competitive abilities with an aggressive encrusting alga, Ramicrusta textilis
}

\author{
Karli J. Hollister ${ }^{1}$ (D) Rosmin S. Ennis $^{1} \cdot$ Heather L. Spalding $^{2} \cdot$ Paul W. Gabrielson $^{3}$ • \\ Tyler B. Smith ${ }^{1}$
}

Published online: 23 September 2021

(c) Springer-Verlag GmbH Germany, part of Springer Nature 2021

\section{Correction to: Coral Reefs \\ https://doi.org/10.1007/s00338-021-02172-0}

Figure 2 was rendered incorrectly in the original publication and has been thus corrected.

The original article can be found online at https://

doi.org/10.1007/s00338-021-02172-0.

Karli J. Hollister

karlihollister@gmail.com

1 Center for Marine and Environmental Studies, University of the Virgin Islands, 2 John Brewers Bay, Saint Thomas, VI 00802, USA

2 Department of Biology, College of Charleston, 66 George Street, Charleston, SC 29424, USA

3 Department of Biology and Herbarium, University of North Carolina Chapel Hill, Coker Hall CB-3280, 120 South Rd, Chapel Hill, NC 27599-3280, USA 
Fig. 2 Map of the southwest side of St. Thomas with study sites. Shape indicates which study corresponds to which sites (square $=$ Study 1 only, triangle = Study 1 and Study 2, circle = Study 2 only). Gray areas show landmasses and color indicates depth. Inset shows average linear growth rates of Ramicrusta textilis $( \pm \mathrm{SE})$ on controls and Siderastrea siderea colonies across sites from Study 2

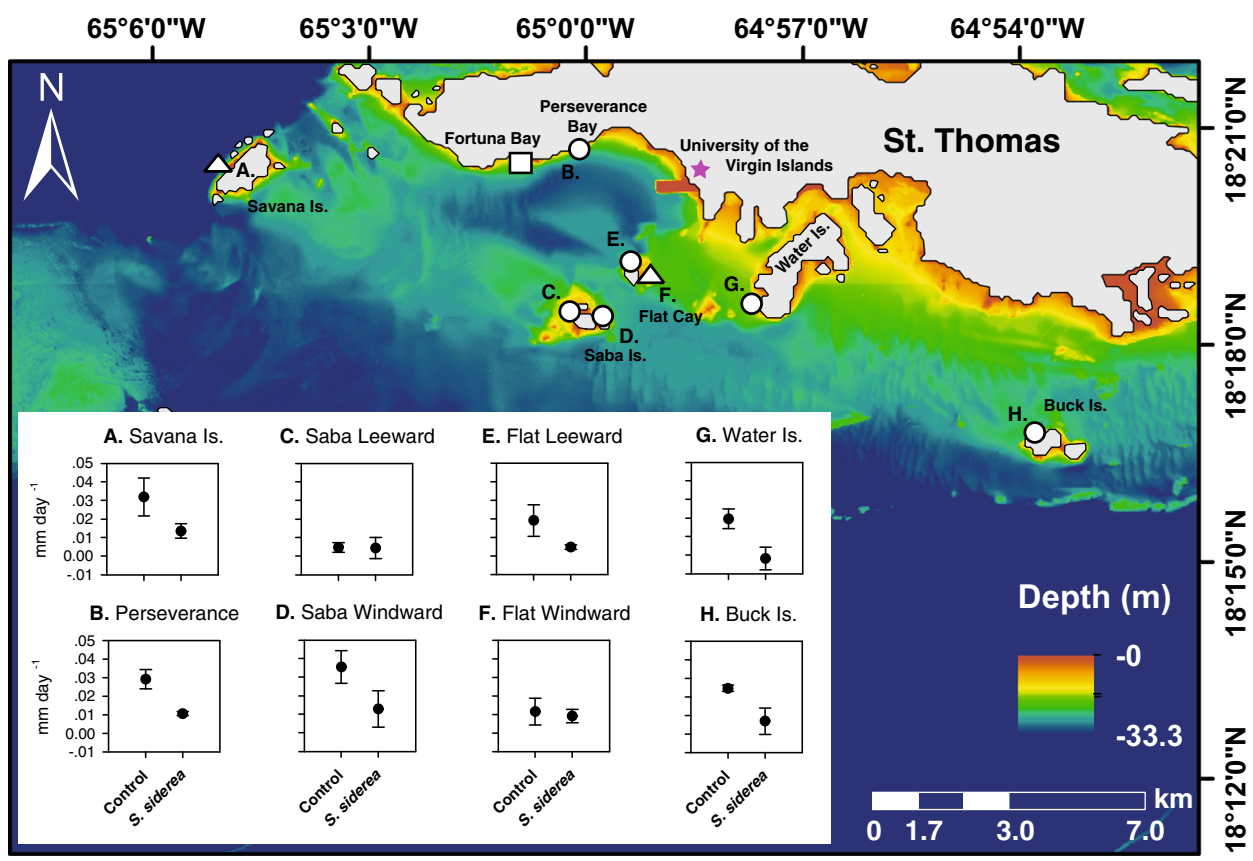

Publisher's Note Springer Nature remains neutral with regard to jurisdictional claims in published maps and institutional affiliations. 